\title{
Analytical study of cylindrical tanks including soil-structure interaction
}

\section{Estudo analítico de tanques cilíndricos incluindo interação solo-estrutura}
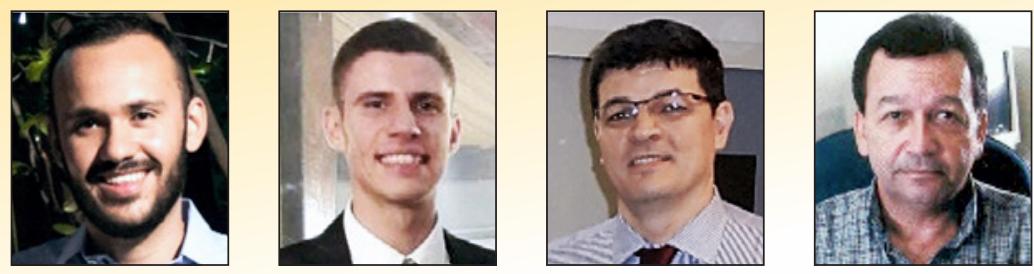

R. L. C. SILVA a engrafaelleandro@hotmail.com https://orcid.org/0000-0003-3591-1309

G. B. MARQUES b glauberbatistamarques@gmail.com https://orcid.org/0000-0001-6170-5926

E. N. LAGES c enl@iccv.ufal.br https://orcid.org/0000-0001-6704-4057

S. P. C. MARQUES smarques@lccv.ufal.br https://orcid.org/0000-0003-3476-0289

\begin{abstract}
An analytical study aiming the design of cylindrical liquid storage tanks resting on deformable foundations is developed in this work. The soil under the tanks is modeled as an elastic linear medium. The cylindrical wall is considered rigidly connected to the plate foundation. Here, concrete tanks are emphasized, although the study can be extended to other construction materials. For the analysis of the design forces acting on the tanks, efficient and simplified approximate expressions are derived based on rigorous analytical theories for thin shells and circular plate on elastic foundations. To verify the proposed approximate expressions and investigate the influence of the foundation deformability on displacements and design forces, parametric analyses of concrete tanks with different soil stiffness values are presented. The results illustrate the strong influence of the foundation stiffness on the tank design quantities and a very good performance of the simplified expressions.
\end{abstract}

Keywords: concrete cylindrical tank, interaction soil-structure, elastic foundation, structural design.

\section{Resumo}

Um estudo analítico voltado para o projeto de tanques cilíndricos para armazenagem de líquidos, apoiados sobre fundação deformável, é desenvolvido neste trabalho. O solo sob os tanques é modelado como um meio elástico linear. A parede cilídrica é considerada rigidamente conectada à placa de fundação. Aqui, tanques de concreto são enfatizados, mas o estudo pode ser estendido para outros materiais de construção. Para a análise dos esforços atuantes sobre os tanques, eficientes e simplificadas expressões aproximadas são deduzidas com base em teorias analíticas rigorosas para cascas delgadas e placas circulares sobre fundações elásticas. Para verificar as expressões aproximadas propostas e investigar a influência da deformabilidade das fundações sobre os esforços e deslocamentos, análises paramétricas de tanques de concreto com diferentes valores de rigidez do solo são apresentadas. Os resultados ilustram a forte influência da rigidez da fundação sobre grandezas de projeto dos tanques e um desempenho muito bom das expressões aproximadas.

Palavras-chave: tanques cilíndricos de concreto, interação solo-estrutura, fundação elástica, projeto estrutural.

Faculdade de Tecnologia de Alagoas (FAT), , Maceió, AL, Brasil

Fentro de Tecnologia, Universidade Federal de Alagoas, Maceió, AL, Brasil;

Laboratório de Computação Científica e Visualização, Centro de Tecnologia, Universidade Federal de Alagoas, Maceió, AL, Brasil.

Received: 15 Feb 2018 • Accepted: 09 Apr 2018 • Available Online:

This is an open-access article distributed under the terms of the Creative Commons Attribution License 


\section{Introduction}

Cylindrical circular concrete tanks resting on the ground are commonly used in water-supply system and wastewater treatment plants. For reasons of simplification of design and mechanical behavior, it is desirable that at the ground level the soil provides condition of firm foundation. However, this condition may not be available and, then, in most cases the tanks are designed and constructed on deformable soils. Several researchers have shown that the deformability of the soil under the base slab has a strong influence on the forces and moments acting along the tank walls. To evaluate this influence, Kukreti et al. [1] developed an analytical study on the behavior of a cylindrical tank resting on an isotropic elastic soil medium. They assumed an approximate power series expansion for the base slab deflection and applied the principle of minimum potential energy for evaluating the unknown series coefficients. The results of a numerical example were verified using a finite element solution. After, Kukreti and Siddiqi [2] presented a similar analytical study including foundation-superstructure interaction

using the differential quadrature method. El Mezaini [3] studied the effects of soil-structure interaction on the behavior of cylindrical tanks using finite element analysis. This study showed that the soil stiffness, as well as the base geometries, has significant influence on the design forces of the tanks. These finite element results also indicated great discrepancies when compared with the values obtained from design coefficients provided by the Portland Cement Association [4], which is a popular tool for the design of cylindrical tanks. Vichare and Inamdar [5] used an analytical formulation based on the thin shell and plates on elastic foundation theories for the analysis of cylindrical tanks founded on uniform deformable soil with different levels of stiffness. To obtain the design forces of cylindrical tanks with flat base slab, these later researchers combined the complete solution for the circular plate on elastic foundation given by Timoshenko and Woinowsky-Krieger [6] with results due to Kelkar and Sewell [7]. As results, Vichare and Inamdar [5] presented complex analytical expressions in terms of Bessel functions for evaluating displacements, moments and forces in the cylindrical wall and base slab. For a numerical example, the authors used a finite element solution to verify the analytical expressions. Mistrikova and Jendzelovsky [8] analyzed the behavior of cylindrical tanks considering their interactions with different types of subsoil. Dehadrai and Ingle [9] employed a finite element code to analyze cylindrical water tanks resting on an elastic soil medium with varying stiffness. More recently, Das and Deb [10] used the concentric equivalent ring method to study the behavior of a cylindrical storage tank resting on a stone column-improved ground. A recent analytical study about cylindrical tank on deformable foundation was also developed by Silva [11].

All these studies have shown a great influence of the soil stiffness on the forces and moments in the tank wall and base plate. To avoid problems, such as leakage, groundwater pollution and corrosion of the reinforcing steel, the design of the concrete tanks must usually be controlled by rigorous serviceability criteria. Then, an accuracy evaluation of the design forces and moments is very important. For this reason, a realistic value of the soil stiffness and the soil-structure interaction effects must be considered.

This paper presents a practical analytical study on structural be- havior of cylindrical liquid storage tanks resting on deformable foundation. The studied tanks have their walls rigidly connected to the plate foundation and the soil is supposed as a linear elastic medium represented by the Winkler model. The study has as focus an investigation about the influence of the soil stiffness on the tank behavior, as well as, the derivation of simple and efficient approximate expressions to obtain the relevant displacements and forces used in the structural design. The idea is to provide to the designers efficient and mathematically simple expressions obtained by elimination of the complex Bessel functions appearing in Vichare and Inamdar [5] formulation. To investigate the influence of the foundation deformability on the important design quantities, a cylindrical tank rested on soils with four different levels of stiffness (soft, medium, stiff and very stiff) is analyzed and the results are presented and discussed. The efficiency of the proposed simplified expressions is also verified from a parametric analysis involving a very large range of soil stiffness levels. The results demonstrate the strong influence of the foundation stiffness on the tank design quantities. The comparative analyses between the closed and approximate solutions show a very good performance of the simplified expressions.

\section{Preliminary considerations}

Figure 1 shows the typical cylindrical ground-water tanks considered in this study. The tanks have a height $\mathrm{H}$ and a diameter $2 \mathrm{R}$ and rest on uniform deformable soils. The flat base slab and the wall have constant thicknesses $t$ and $h$, respectively, and are monolithically connected. The tank material is assumed as homogeneous, isotropic and linear elastic with elasticity modulus $E$ and Poisson's ratio $v$. The soil is modeled by continuously distributed vertical elastic springs with stiffness $\mathrm{k}_{\mathrm{s}}$ (Winkler's foundation) as shown in Fig. 2.

In the tanks, the considered loadings are hydrostatic pressure and self-weight of the wall and base slab. In addition to the wall selfweight, a symmetrical vertical distributed load on the top of the wall due to a roof, for instance, can be applied. The forces and

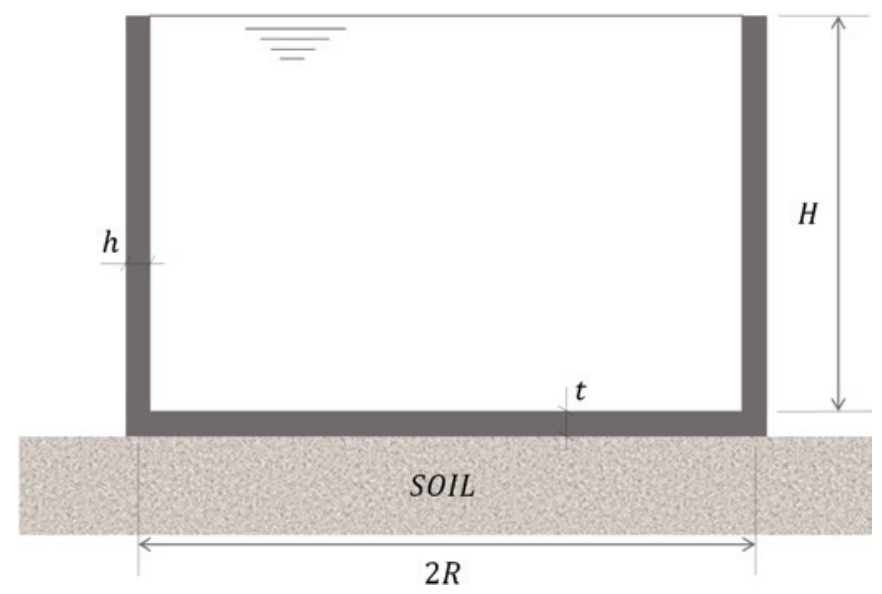

Figure 1

Schematic representation of the cylindrical tank on deformable foundation 


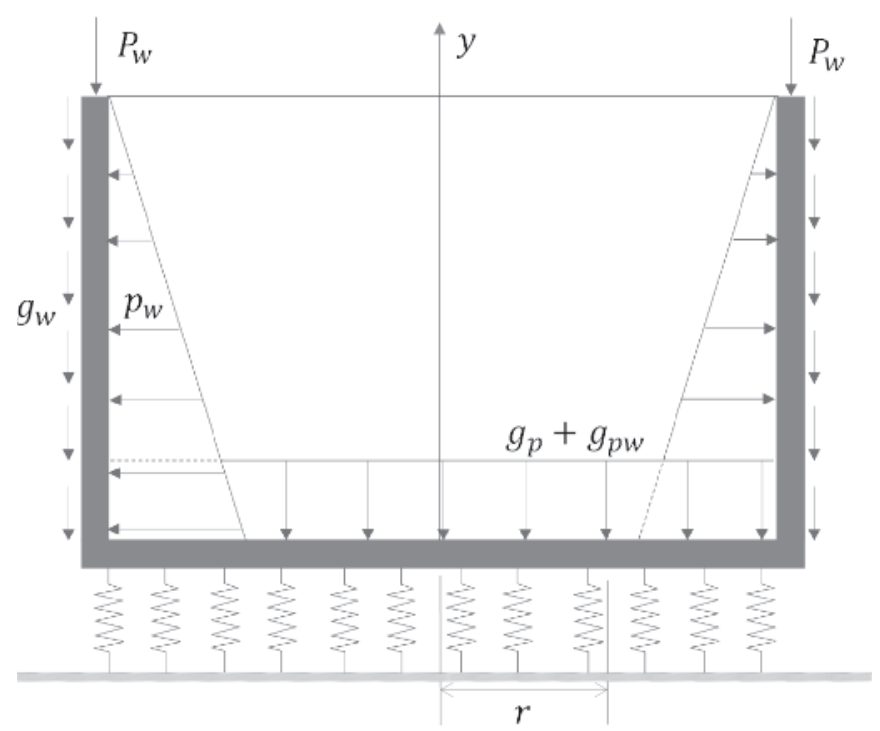

\section{Figure 2}

External loadings acting on the tank and elastic springers

moments acting on the wall and base plate are illustrated in Fig 3. In this figure, $M_{0}, H_{0}$ and $Q_{0}$ represent the interaction forces between the tank wall and the plate foundation. Hence, the plate foundation is subjected to the self-weight $g_{p}=\gamma_{m}$ t, liquid pressure $g_{p w}=\gamma_{1} \mathrm{H}$ and interaction forces and moments $\left(M_{0}, H_{0}\right.$ and $\left.Q_{0}\right)$ distributed along the external perimeter. $\gamma_{\mathrm{m}}$ and $\gamma_{1}$ are the weights per unit volume of the tank material and stored liquid, respectively. The cylindrical wall is subjected to the reactions of those interaction forces and moments at the bottom end, hydrostatic load $p_{w}=\gamma_{1}(H-$ y) on the internal side, self-weight $g_{w}=\gamma_{m} h$ and an axisymmetric vertical load $\mathrm{P}_{\mathrm{w}}$ distributed along the superior end.

The plate foundation subjected to those mentioned loads exhibits greater settlement at its perimeter than at the center. This differential settlement occurs due to the presence of the forces and mo- ments $Q_{0}$ and $M_{0}$ distributed along the plate boundary. Assuming the soil as a homogeneous medium, the uniform loadings $g_{p}$ and $\mathrm{g}_{\mathrm{pw}}$ do not create bending moments, shear or tension forces on the plate. Hence, they only cause uniform settlements along the plate and, consequently, do not influence the design forces and moments. On the other hand, due to the rigid connection between the wall and the plate foundation, the differential settlements can have a great influence on the bending moments, shear and normal forces acting along the tank wall.

The interaction force $Q_{0}$ is statically determined in function of the known loads $P_{w}$ and $g_{w}$ by the expression:

$Q_{0}=P_{w}+g_{w} H=P_{w}+\gamma_{m} h H$

On the contrary, the interaction force $\mathrm{H}_{0}$ and moment $\mathrm{M}_{0}$ are not statically determined and their computation can be made imposing compatibility conditions between the horizontal displacements and rotations of the plate foundation and tank wall along their junction (Billington [12]; Vichare and Inamdar [5]). Through this procedure and using flexibility coefficients of thin cylindrical shells and circular plates on elastic base, Vichare and Inamdar [5] derived complex equations for evaluating $\mathrm{M}_{0}$ and $\mathrm{H}_{0}$. In the next section, these equations are used as basis for derivation of very simple and efficient equations to evaluate the interaction forces and moments acting along the tank wall-foundation plate junction.

\section{Analytical procedures}

\subsection{Evaluation of interaction forces at the wall-foundation plate joint}

For a circular plate rested on an elastic base with stiffness $k_{s}$ and subjected to a symmetrical external loading $q(r)$, the vertical deflections (settlements) $\mathrm{w}$ are given by (Timoshenko and Woinowsky-Krieger [6]):

$\left(\frac{d^{2}}{d r^{2}}+\frac{1}{r} \frac{d}{d r}\right)\left(\frac{d^{2} w}{d r^{2}}+\frac{1}{r} \frac{d w}{d r}\right)=\frac{q(r)-k_{s} w}{D_{p}}$

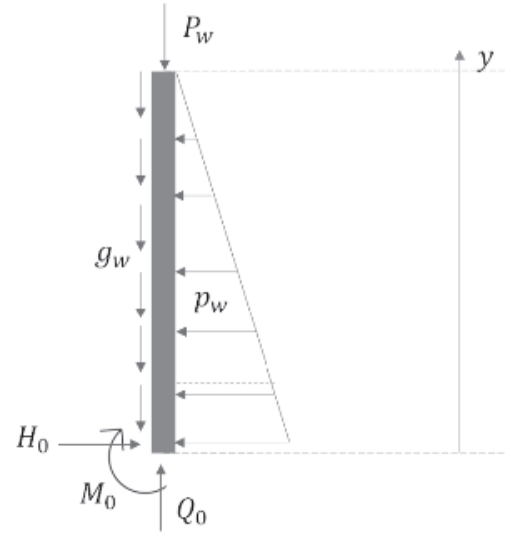

(a)

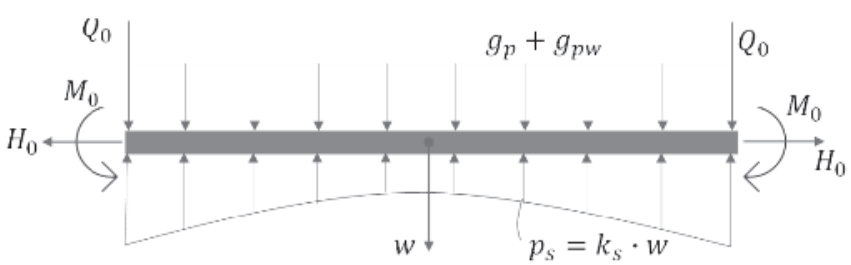

(b)

\section{Figure 3}

Free body diagrams of the cylindrical wall (a) and base plate (b) 


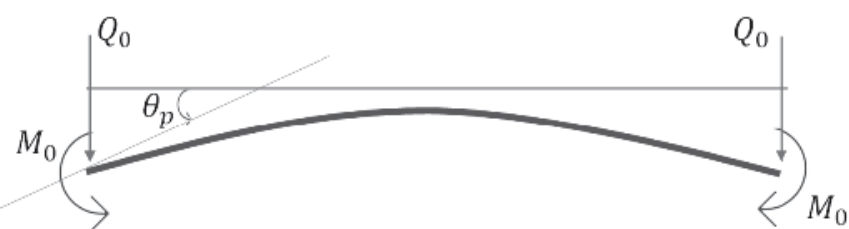

Figure 4

Rotation at the plate edge

where $r$ is the radial coordinate and $D_{p}$ indicates the flexural rigidity of the plate defined in the form:

$D_{p}=\frac{E t^{3}}{12\left(1-v^{2}\right)}$

As described above, a uniform continuously distributed load $q(r)$ does not influence the design forces and moments and, then, it can be made equal to zero in eq. (2). For this case, the solution for the plate deflection $w$ can be written as (Vichare and Inamdar [5]):

$w=A_{1} \operatorname{ber}_{0}\left(\frac{r}{l}\right)+4 A_{2} \operatorname{bei}_{0}\left(\frac{r}{l}\right)$

where, in general, ber ${ }_{n}(x)$ and bei ${ }_{n}(x)$ represent, respectively, the real and imaginary parts of the Bessel function of the first kind of order $n, J_{n}\left(i^{3 / 2} x\right)$, (see Wylie and Barrett [13]). The parameter I appearing in eq. (4) is defined as:

$l=\sqrt[4]{D_{p} / k_{s}}$

The constants $A_{1}$ and $A_{2}$ are determined using the following boundary conditions at $r=\mathrm{R}$ :

$\left(\frac{d^{2} w}{d r^{2}}+\frac{v}{r} \frac{d w}{d r}\right)_{r=R}=\frac{M_{0}}{D_{p}}$

$\left[\frac{d}{d r}\left(\frac{d^{2} w}{d r^{2}}+\frac{1}{r} \frac{d w}{d r}\right)\right]_{r=R}=-\frac{Q_{0}}{D_{p}}$

The expressions of $A_{1}$ and $A_{2}$ can be found in Vichare and Inamdar [5]. Using eq. (4), the vertical rotation at the plate edge due to both $\mathrm{Q}_{0}$ and $\mathrm{M}_{0}$ can be written as (see Fig. 4):

$\theta_{p}=\left(\frac{d w}{d r}\right)_{r=R}=\frac{G_{1}(\alpha) l}{D_{p}} M_{0}+\frac{G_{2}(\alpha) l^{2}}{D_{p}} Q_{0}$

being $\alpha=\mathrm{R} / \mathrm{I}$ and

$G_{1}(\alpha)=\frac{\sqrt{2} \alpha C_{1}}{\alpha\left[C_{2} \text { ber }_{0}(\alpha)+C_{3} b e i_{0}(\alpha)\right]+\sqrt{2}(1-v) C_{1}}$

$G_{2}(\alpha)=\frac{C_{3} \text { ber }_{0}(\alpha)-\alpha C_{2} \text { bei }_{0}(\alpha)}{\alpha\left[C_{2} \text { ber }_{0}(\alpha)+C_{3} \text { bei }_{0}(\alpha)\right]+\sqrt{2}(1-v) C_{1}}$

with $C_{1}=\operatorname{ber}_{1}(\alpha)^{2}+\operatorname{bei}_{1}(\alpha)^{2}, C_{2}=\operatorname{ber}_{1}(\alpha)-\operatorname{bei}_{1}(\alpha)$ and $C_{3}=\operatorname{ber}_{1}(\alpha)$ $+\operatorname{ber}_{1}(\alpha)$.

The radial displacement produced by the radially distributed forces $\mathrm{H}_{0}$ at the edge of the circular plate is given by:

$\delta_{p}=-\frac{(1-v) R}{E t} H_{0}$

For the cylindrical wall, the horizontal displacement $\delta_{w}$ and rotation $\theta_{\mathrm{w}}$ at the bottom can be computed by the following expressions (Billington [12]):

$\delta_{w}=2 \beta \frac{R^{2}}{E h} H_{0}-2 \beta^{2} \frac{R^{2}}{E h} M_{0}-\frac{\gamma_{l} H R^{2}}{E h}-\frac{v \gamma_{m} H R}{E}-\frac{v P_{w} R}{E h}$

$\theta_{w}=-2 \beta^{2} \frac{R^{2}}{E h} H_{0}+4 \beta^{3} \frac{R^{2}}{E h} M_{0}+\frac{\gamma_{l} R^{2}}{E h}+\frac{v \gamma_{m} R}{E}$

being:

$\beta^{4}=\frac{3\left(1-v^{2}\right)}{R^{2} h^{2}}$

Now, applying the displacement compatibility conditions at the base plate - wall junction, $\delta_{w}=\delta_{p}$ and $\theta_{w}=\theta_{p}$, the values of $\mathrm{M}_{0}$ and $\mathrm{H}_{0}$ can be obtained by the expressions:

$M_{0}=\frac{1}{B_{1}+B_{2} G_{1}(\alpha)}\left[B_{3}+B_{4} G_{2}(\alpha)\right]$

$H_{0}=\frac{\left(v \gamma_{m} h+\gamma_{l} R\right) H+v P_{w}+2 \beta^{2} R M_{0}}{2 \beta R+(1-v) \frac{h}{t}}$

where

$B_{1}=1+\frac{\beta^{3} t^{2} R}{3(1+v)}$

$B_{2}=-\left(1+B_{1}\right) \beta l\left(\frac{h}{t}\right)^{3}$

$B_{3}=\frac{\left(v \gamma_{m} h+\gamma_{l} R\right)\left(2 \beta H-1-B_{1}\right)+2 v \beta P_{w}}{4 \beta^{3} R}$

$B_{4}=-B_{2} l H h \gamma_{m}$

These equations have been determined from the closed analytical formulation derived by Vichare and Inamdar [5]. They are exact expressions, however, the use of them requires the evaluation of the complex functions $G_{1}(\alpha)$ and $G_{2}(\alpha)$. For the current practical applications, it is interesting to found simple and accurate expressions that allow obtaining the values of $\mathrm{M}_{0}$ and $\mathrm{H}_{0}$. Here, the complicated eq. (15) is replaced by the simplified expression:

$M_{0}=\frac{1}{B_{1}+B_{2} \widetilde{G}_{1}(\alpha)}\left[B_{3}+B_{4} \widetilde{G}_{2}(\alpha)\right]$

where the complex functions $G_{1}(\alpha)$ and $G_{2}(\alpha)$ are substituted for approximate and very simple functions $\widetilde{G}_{1}(\alpha)$ and $\widetilde{G}_{2}(\alpha)$, respectively, being:

$\widetilde{G}_{1}(\alpha)=-\frac{0.570+1.414 \alpha^{0.968}}{0.028+\alpha^{0.968}}$

$\widetilde{G}_{2}(\alpha)=-\frac{1.720+0.999 \alpha^{0.912}}{1.375+\alpha^{0.912}}$

These later equations have been fitted for $\alpha \geq 4$ by using a linear regression method known as MMF model (Morgan et al. [14]). It is worth noticing that, for usual geometrical dimensions of base plates and soil stiffnesses, the values of the parameter $\alpha$ belong to that interval. 
Comparisons between those exact and approximate functions for the interval $4 \leq \alpha \leq 100$ show relative maximum errors of only $0.86 \%$ and $0.44 \%$ for $\widetilde{G}_{1}(\alpha)$ and $\widetilde{G}_{2}(\alpha)$, respectively, occurring at $\alpha=4$. The parametric analysis shown in the next section demonstrates the efficiency of the proposed approximate expression (21) for the computation of the design forces and moments of a cylindrical tank with a large range of soil stiffness. The interaction force $\mathrm{H}_{0}$ can be readily calculated from eq. (16) using the approximate value of $M_{0}$.

\subsection{Computation of displacements and forces along of the cylindrical wall}

For the axisymmetrical forces shown in Fig. 3(a), the middle surface of the cylindrical wall presents vertical and radial displacements $u$ and $v$, respectively. Using the classical theory of thin shells (Billington [12]), the radial displacement of the wall can be obtained in function of the interaction forces at the junction of the tank wall and plate foundation by:

$v(y)=-\frac{e^{-\beta y}}{2 \beta^{3} D_{w}}\left[\beta M_{0}(\cos \beta y-\sin \beta y)-H_{0} \cos \beta y\right]-\frac{\gamma_{l} R^{2}}{E h}(H-y)$

where $D_{w}$ is the flexural rigidity of the cylindrical shell given by:

$D_{w}=\frac{E h^{3}}{12\left(1-v^{2}\right)}$

In eq. (24), the radial displacement $v$ is considered as positive when it is directed to the interior of the cylindrical shell.

The hoop force $N_{\theta}$ and the vertical bending moment $M_{y}$ acting along the wall can be obtained by:

$N_{\theta}=-\frac{E h v}{R}$

$M_{y}=-D_{w} \frac{d^{2} v}{d y^{2}}$

Here, $M_{y}$ is taken as positive if it produces tension stress in the internal side of the wall whereas tension hoop force $\mathrm{N}_{\theta}$ is considered as positive (Fig. 5)

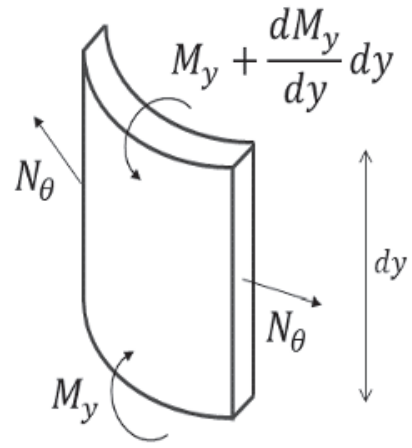

(a)
Additionally, the cylindrical wall is also submitted to the circumferential horizontal bending moment $\mathrm{M}_{\theta}$ and the transverse shearing force $Q_{y}$ defined by:

$M_{\theta}=v M_{y}$

$Q_{y}=-D_{w} \frac{d^{3} v}{d y^{3}}$

\subsection{Approximate analysis of the plate foundation}

The deflection $w$ of the circular plate foundation is given by eq. (4), where the integration constants $A_{1}$ and $A_{2}$ are dependent upon the edge conditions related to the moment $\mathrm{M}_{0}$, eq. (6), and shearing force $Q_{0}$, eq. (7). The radial bending moments $M_{r}$ and shearing forces $Q_{r}$ acting on the plate can be obtained by the following relations (Fig. 5):

$M_{r}=-D_{p}\left(\frac{d^{2} w}{d r^{2}}+\frac{v}{r} \frac{d w}{d r}\right)$

$Q_{r}=D_{p}\left[\frac{d}{d r}\left(\frac{d^{2} w}{d r^{2}}+\frac{1}{r} \frac{d w}{d r}\right)\right]$

To simplify the computation of the deflections, bending moments and shearing force of the plate, the Bessel functions appearing in eq. (4) can be approximated by the asymptotic expressions (Timoshenko and Woinowsky-Krieger [6]):

$\operatorname{ber}_{0}(x) \cong \frac{e^{x / \sqrt{2}}}{\sqrt{2 \pi x}} \cos \left(\frac{x}{\sqrt{2}}-\frac{\pi}{8}\right)$

$b e i_{0}(x) \cong \frac{e^{x / \sqrt{2}}}{\sqrt{2 \pi x}} \sin \left(\frac{x}{\sqrt{2}}-\frac{\pi}{8}\right)$

It is worth observing that these two approximate relations are valid for not very small values of the argument $x$ as can be seen in Fig. 6. This figure shows that the approximations (32) and (33) do not work well only for a small region close to the origin of the $x$-axis. However, for the circular plate region of usual particular interest in

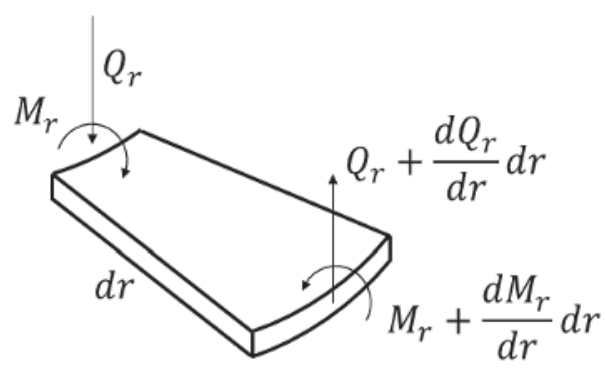

(b)

\section{Figure 5}

Hoop force and vertical bending moment in the wall (a) and radial bending moment and shear force in the plate (b) 


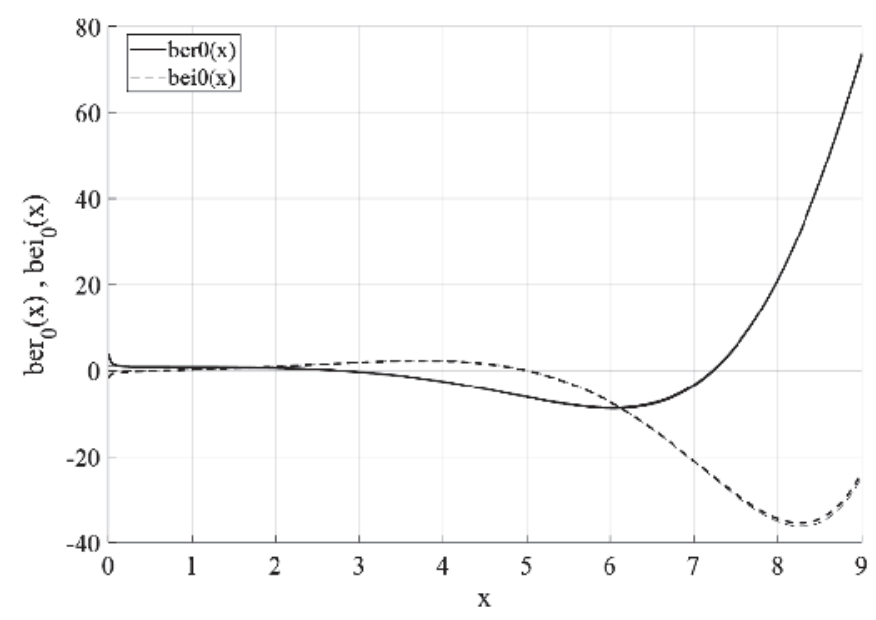

\section{Figure 6}

Exact and approximate (thicker lines) functions $\operatorname{ber}_{0}(x)$ and $\operatorname{bei}_{0}(x)$

structural designs such approximations provide accurate predictions as shown in the next section.

Introducing eqs. (32) and (33) into eq. (4) and using the boundary Introducing eqs. (32) and (33) into eq. (4) and using the boundary conditions given by the relations (6) and (7), the constants $A_{1}$ and $A_{2}$ are readily determined and, consequently, the expression of the plate deflection is obtained. With the known plate deflection $\mathrm{w}$, the bending moments and shearing forces can be computed through the expressions (30) and (31).

\section{Numerical examples and discussion of results}

In order to illustrate the influence of the soil deformability on the design mechanical quantities and verify the approximate expressions presented in this paper, a concrete cylindrical water tank rested on a soil with four different levels of deformability (soft, medium, stiff and very stiff) was analyzed. The following numerical data were considered (see Fig. 1):

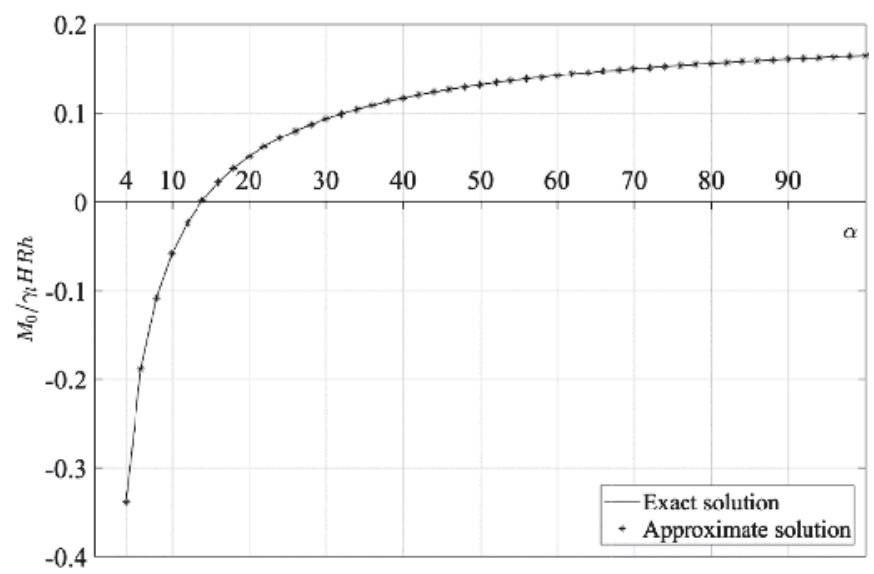

\section{Figure 7}

Variation of the moment at the base plate-wall junction in function of $\alpha$

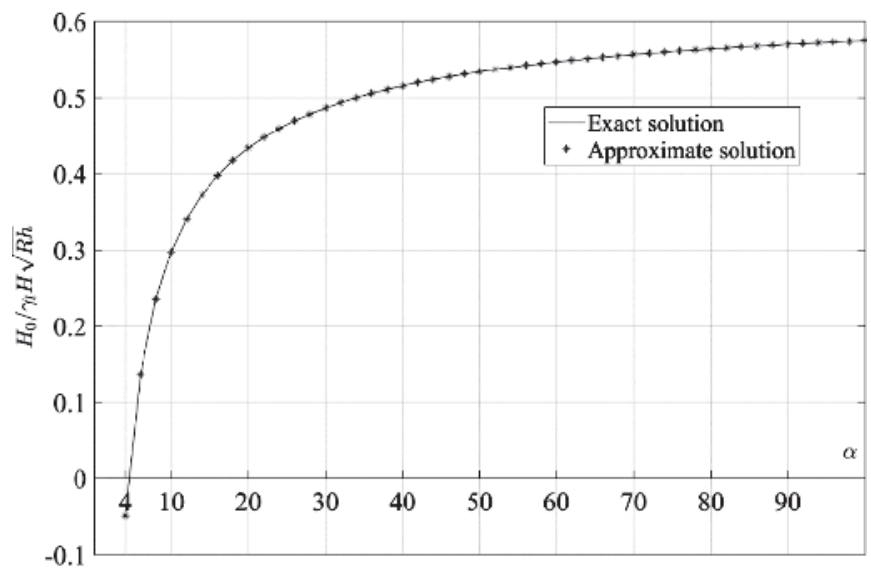

\section{Figure 8}

Variation of the shear force at the base plate-wall junction in function of $\alpha$

Geometrical dimensions: $\mathrm{R}=658.75 \mathrm{~cm}, \mathrm{t}=\mathrm{h}=17.50 \mathrm{~cm}$ and $\mathrm{H}=350 \mathrm{~cm}$.

Concrete properties: $\mathrm{E}=20 \mathrm{GPa}, \mathrm{v}=0.2$ and $\gamma_{\mathrm{m}}=25 \mathrm{kN} / \mathrm{m}^{3}$.

Soil stiffness $\mathrm{k}_{\mathrm{s}}\left(\mathrm{kN} / \mathrm{m}^{3}\right): 25,000,50,000,100,000$ and $10^{10}$.

Weight per unit volume of water: $\gamma_{1}=10 \mathrm{kN} / \mathrm{m}^{3}$.

To demonstrate the performance of the proposed approximate functions $\widetilde{G}_{1}(\alpha)$ and $\widetilde{G}_{2}(\alpha)$ in replacement of the complex functions $G_{1}(\alpha)$ and $G_{2}(\alpha)$, a parametric analysis of $M_{0}$ for a large interval of $\alpha(4 \leq \alpha \leq 100)$ was made. Figure 7 shows the comparison between the exact and approximate curves of $M_{0}$ obtained by eqs. (15) and (21), respectively. Using the exact and approximate values of $M_{0}$ into eq. (16), the curves corresponding to the force $H_{0}$ as function of the parameter $\alpha$ can be found (Fig. 8). As can be seen, the exact and approximate functions provide practically coincident values for the design forces at the base plate-wall junction. Figure 7 also shows that there is a value of the parameter $\alpha$ for which the moment $M_{0}$ is null, i. e., a value corresponding to the transition of

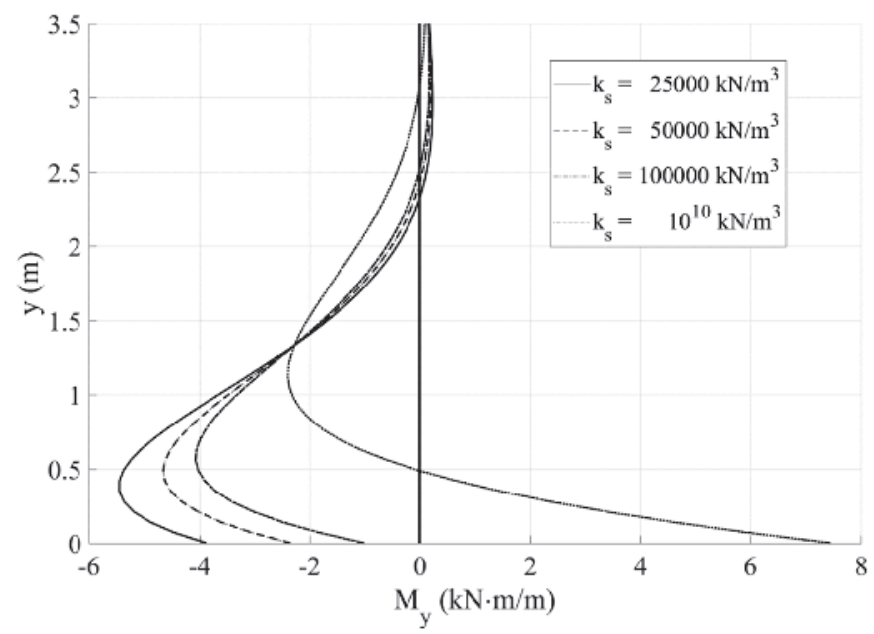

Figure 9

Bending moment $\mathrm{M}_{\mathrm{y}}$ along the wall for different soil stiffness 


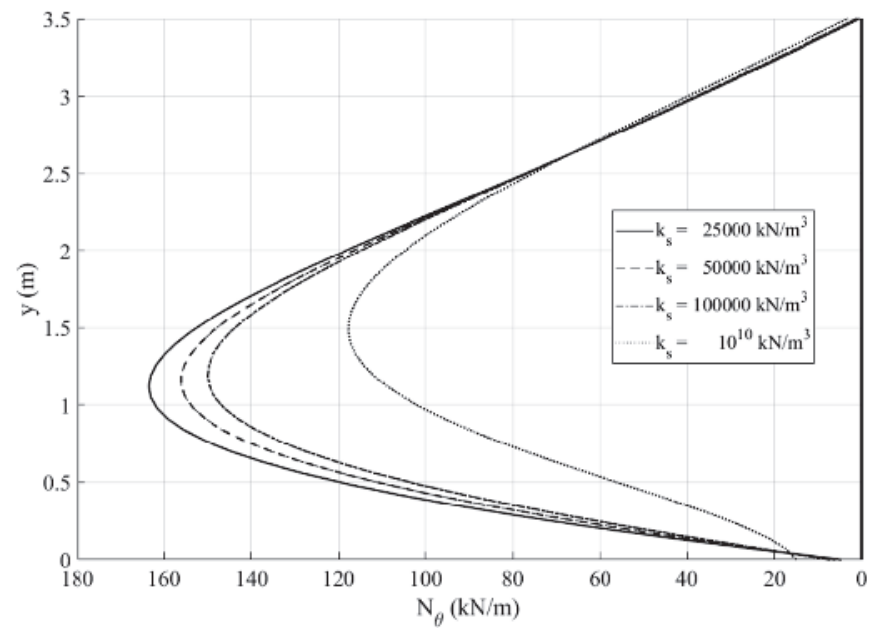

Figure 10

Hoop force $\mathrm{N}_{\theta}$ along the wall for different soil stiffness

the moment sign. For the present case, this value is equal to 13.86 , which corresponds to a ratio $D_{p} /\left(k_{s}=0.051 \mathrm{~m}^{4}\right.$ or a soil stiffness $\mathrm{k}_{\mathrm{s}}=182,440.60 \mathrm{kN} / \mathrm{m}_{3}$.

To verify the effects of the soil deformability on the design forces and moments acting along the wall and base plate, the tank was analyzed as rested on four soil types, classified as soft, medium, stiff and very stiff, with stiffness $\left(k_{s}\right): 25,000 \mathrm{kN} / \mathrm{m}^{3}, 50,000 \mathrm{kN} / \mathrm{m}^{3}$, $100,000 \mathrm{kN} / \mathrm{m}^{3}$ and $10^{10} \mathrm{kN} / \mathrm{m}^{3}$, respectively. This later stiffness value was used to simulate the conditions of an infinitely rigid soil. The results of forces, moments and deflections corresponding to the different soil stiffness are represented in Figs. 9-13. The exact and approximate curves of $\mathrm{M}_{\mathrm{y}}$ and $\mathrm{N}_{\theta}$ for the same value of the soil stiffness are practically coincident so that the differences between them cannot be visualized in Figs. 9 and 10. The results show the significant influence of the elastic foundation on the bending moments and hoop forces developed in the tank wall. It is very im-

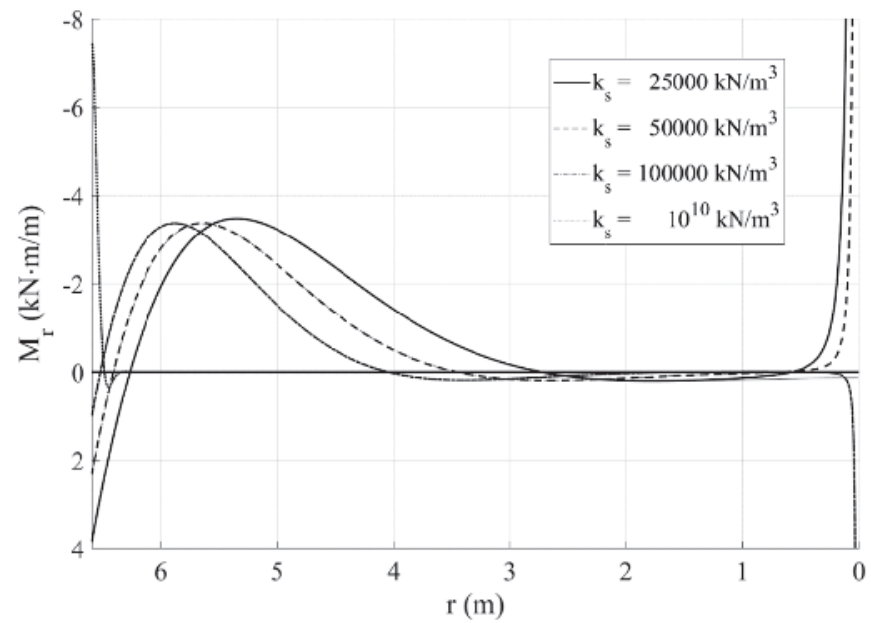

Figure 11

Radial bending moment $\mathrm{M}_{\mathrm{r}}$ in the base plate for different soil stiffness

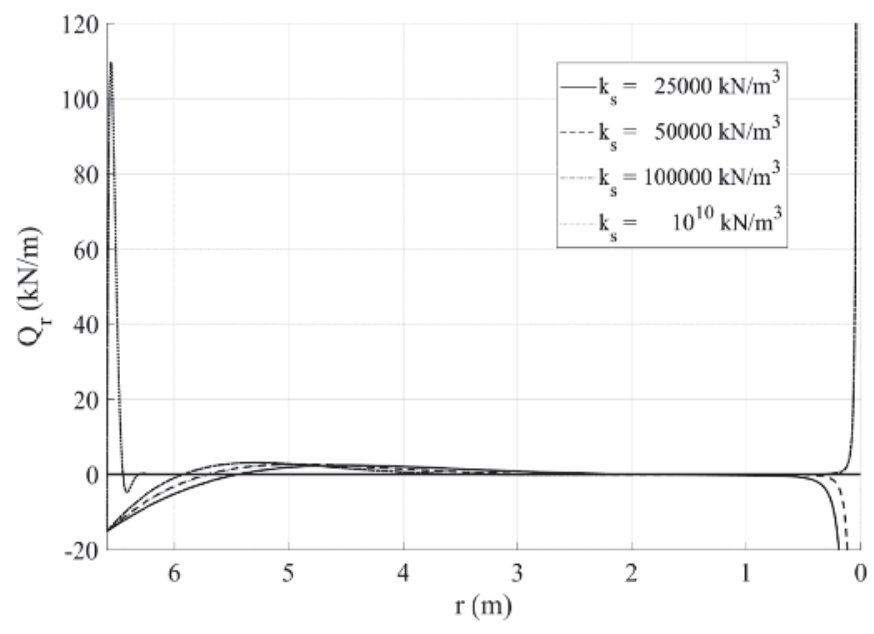

Figure 12

Radial shear force $Q_{r}$ in the base plate for different soil stiffness

portant to observe that even for soils classified as rigid the actual bending moment distribution along the wall can be completely different from that obtained through the usual design assumptions by which the lower edge of the wall is assumed as built into an absolutely rigid foundation or the plate base is supported by a soil infinitely rigid. The very small bending moments appearing at the top of the wall in Fig. 9 are justified by the used simplification of cylindrical shell enough long so that each edge (top and bottom) can be treated independently. This assumption is commonly employed in design procedures when $\beta \mathrm{H}>\pi$.

Figures 11 and 12 show the distributions of the approximate radial bending moments and radial shear forces, respectively, for the circular base plate. As described above and observed in Figs. 11 and 12, the approximate solution provides discrepant results for regions very close to the plate center. However, for the rest of

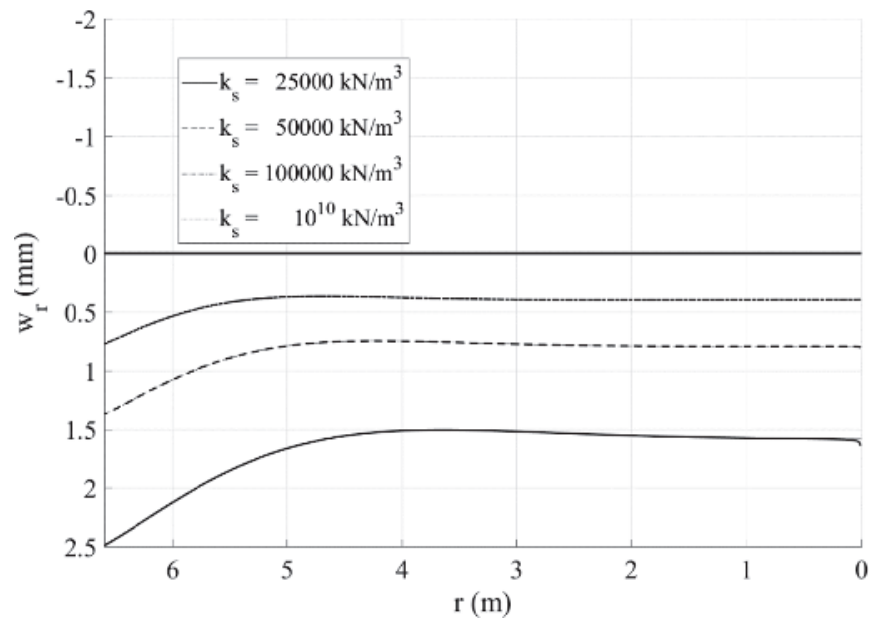

Figure 13

Vertical deflection $w_{r}$ in the base plate for different soil stiffness 
the plate the approximate and exact solutions present a very good agreement for all adopted levels of soil stiffness, so that the differences between corresponding curves are not graphically visible. It is interesting to emphasize that in design of tanks rested on the ground the shear forces and bending moments in the region close to the plate center usually do not have so much significance.

The results of the plate vertical displacements are shown in Fig. 13. In this figure the differences between the curves of the approximate (thicker lines) and exact (thinner lines) deflections are not visible, except in a small region very close to the plate center. It is also observed that the magnitude of such differences decreases with the increase of the soil stiffness. Figures 11 - 13 show that the disturbances of the approximate solution for the bending moments and shear forces are relatively higher than for the deflections. This occurs because these moments and forces depend on derivatives of the approximate functions given by eqs. (32) and (33).

As illustrated in Fig. 13, a central circular region of the plate, whose size depends on the soil stiffness, holds practically flat. For the same geometrical dimensions and loading, the diameter of such region decreases with the increase of the soil deformability.

The numerical values of maximum and minimum displacements and forces in the tank obtained by exact and approximate solutions are presented in Table 1 for the four soil stiffnesses. As can be seen, the approximate values are in very good agreement with those obtained by the exact solution. The major differences between the corresponding exact and approximated values in Table 1 occur for the base plate, where a largest relative error of ap- proximately $3.15 \%$ is observed in the maximum radial shear force occurring for the softer soil with $\mathrm{k}_{\mathrm{s}}=25,000 \mathrm{kN} / \mathrm{m}^{3}$.

\section{Conclusions}

An analytical study aiming the design of liquid storage circular tanks resting on deformable foundation has been developed. The procedures accounted for the soil-structure interactions. The soil behavior has been modeled by a continuous set of elastic vertical springers. An exact analytical formulation expressed in terms of complex Bessel functions was used as basis for derivation of simplified and efficient approximate expressions to evaluate mechanical quantities which are important for the structural design of the mentioned tanks. Comparisons of results showed that the simplified approximate expressions allow obtaining the displacements, forces and moments along the tank wall with an excellent accuracy in relation to the exact solution. For the analyzed tank, the largest relative difference between corresponding extreme values of displacements and forces in the wall, computed by using the exact and approximate solutions, was $0.143 \%$.

To evaluate the displacements, shear forces and bending moments along the plate foundation, the study used approximate expressions for the real and complex parts of the Bessel functions. The analyses demonstrated that such approximations provide very good results for the important mechanical quantities for the plate design and their unrealistic values are concentrated in a small region near the plate center. A largest relative difference of approximately $3.15 \%$ between

\section{Table 1}

Values of the maximum and minimum forces and displacements of the tank

\begin{tabular}{|c|c|c|c|c|c|c|}
\hline & Units [kN; m] & & $\mathrm{k}_{\mathrm{s}}=25,000$ & $\mathrm{k}_{\mathrm{s}}=50,000$ & $k_{s}=100,000$ & $k_{s}=10^{10}$ \\
\hline \multirow{4}{*}{$M_{y}$} & \multirow{2}{*}{ Max } & Exact & 0.2357 & 0.2011 & 0.1759 & 7.4486 \\
\hline & & Approx. & 0.2356 & 0.2010 & 0.1758 & 7.4486 \\
\hline & \multirow{2}{*}{ Min } & Exact & -5.4531 & -4.6539 & -4.0692 & -2.3899 \\
\hline & & Approx. & -5.4506 & -4.6519 & -4.0680 & -2.3899 \\
\hline \multirow{4}{*}{$\mathrm{N}_{\theta}$} & \multirow{2}{*}{ Max } & Exact & 163.4696 & 156.1208 & 150.0996 & 117.6479 \\
\hline & & Approx. & 163.4556 & 156.1093 & 150.0916 & 117.6479 \\
\hline & \multirow{2}{*}{ Min } & Exact & 0.4911 & 0.8619 & 1.1849 & 3.2336 \\
\hline & & Approx. & 0.4918 & 0.8625 & 1.1853 & 3.2336 \\
\hline \multirow{4}{*}{$\begin{array}{c}v \\
\left(\times 10^{-3}\right)\end{array}$} & \multirow{2}{*}{ Max } & Exact & -0.000924 & -0.001622 & -0.002230 & -0.006086 \\
\hline & & Approx. & -0.000926 & -0.001623 & -0.002231 & -0.006086 \\
\hline & \multirow{2}{*}{ Min } & Exact & -0.311593 & -0.297691 & -0.286313 & -0.224773 \\
\hline & & Approx. & -0.311566 & -0.297668 & -0.286298 & -0.224773 \\
\hline \multirow{4}{*}{$M_{r}$} & \multirow{2}{*}{ Max } & Exact & 3.8802 & 2.3485 & 1.0143 & 0.3255 \\
\hline & & Approx. & 3.8283 & 2.3147 & 0.9924 & 0.3255 \\
\hline & \multirow{2}{*}{ Min } & Exact & -3.4684 & -3.3679 & -3.3658 & -7.4486 \\
\hline & & Approx. & -3.4779 & -3.3755 & -3.3717 & -7.4486 \\
\hline \multirow{4}{*}{$Q_{r}$} & \multirow{2}{*}{ Max } & Exact & 2.2960 & 2.5926 & 3.0254 & 109.5791 \\
\hline & & Approx. & 2.3683 & 2.6413 & 3.0615 & 109.5816 \\
\hline & \multirow{2}{*}{ Min } & Exact & -15.3125 & -15.3125 & -15.3125 & -15.3125 \\
\hline & & Approx. & -15.1756 & -15.1897 & -15.2032 & -15.3026 \\
\hline \multirow{4}{*}{$\begin{array}{c}W_{r} \\
\left(\times 10^{-3}\right)\end{array}$} & \multirow{2}{*}{ Max } & Exact & 2.487558 & 1.368909 & 0.769170 & 0.000848 \\
\hline & & Approx. & 2.489538 & 1.369853 & 0.769621 & 0.000848 \\
\hline & \multirow{2}{*}{ Min } & Exact & 1.507159 & 0.744499 & -0.365083 & 0.000158 \\
\hline & & Approx. & 1.508066 & 0.744847 & -0.365217 & 0.000158 \\
\hline
\end{tabular}


the corresponding extreme values of displacements and forces, computed by exact and approximate solutions, was observed for the maximum radial shear force in the plate.

Comparative analyses of a cylindrical tank rested on soils with different levels of stiffness (soft, medium, stiff and very stiff) demonstrated that the effects of soil-structure interaction have crucial importance for the tank design. The results showed that the critical design forces of the tank are very sensitive to differential settlements of the plate foundation and that even for soils usually classified as rigid the actual resultant forces in the wall can be very different from those obtained through the simplified design procedures in which the soil-structure interactions are neglected.

\section{Acknowledgements}

The authors acknowledge the financial support provided by the Brazilian federal agencies CNPq and CAPES.

\section{References}

[1] Kukreti, AR, Zaman, MM, and Issa, A. Analysis of fluid storage tanks including foundation-superstructure interaction. Applied Mathematical Modelling, v.17, n.12, 1993; p. 618-631.

[2] Kukreti, AR and Siddiqi, ZA. Analysis of fluid storage tanks including foundation-superstructure interaction using differential quadrature method. Applied Mathematical Modelling, v.21, 1997; p. 193-205.

[3] El Mezaini, N. Effects of soil-structure interaction on the analysis of cylindrical tanks. Practice Periodical on Structural Design and Construction, ASCE, v.11, n.1, 2006; p. 50-57.

[4] Portland Cement Association (PCA). Circular concrete tanks without prestressing, Skokie, IL, USA, 1993.

[5] Vichare, S and Inamdar, MM. An analytical solution for cylindrical concrete tank on deformable soil. International Journal of Advanced Structural Engineering, v.2, n.1, 2010; p. 69-90.

[6] TIMOSHENKO, S.P. and WOINOWSKY-KRIEGER, S. Theory of plates and shells, New York: McGraw-Hill, 2ed, 1959, $580 \mathrm{p}$.

[7] KELKAR, V.S. and SEWELL, R.T. Fundamentals of the analysis and design of shell structures, Eaglewood Cliffs: Prentice-Hall Inc., 1987, 510 p.

[8] Mistrikova, Z. and Jendzelovsky, N. Static analysis of the cylindrical tank resting on various types of subsoil. Journal of Civil Engineering and Management, v.18, n.5, 2012; p. 744-751.

[9] Dehadrai, VP and Ingle, RK. Cylindrical water tanks resting on soil of varying stiffness. Practice Periodical on Structural Design and Construction, ASCE, v.21, n.3, 2016; 04016006-1.

[10] Das, AK and Deb, K. Response of cylindrical storage tank foundation resting on tensionless stone column-improved soil. International Journal of Geomechanics, ASCE, v.17, n. 1, 2017; 04016035.

[11] SILVA, R.L.C. Contribuição ao projeto de reservatórios cilíndricos de concreto armado apoiados em base deformável, Maceió, 2017. Dissertação (Mestrado em Engenharia Civil), Universidade Federal de Alagoas, 209 p.
[12] BILLINGTON, D.P. Thin shell concrete structures, New York: McGraw-Hill, 2ed, 1982, 373 p.

[13] WYLIE, C.R. and BARRETT, L.C. Advanced engineering mathematics, New York: McGraw-Hill Companies, 6ed, 1995, $1103 \mathrm{p}$.

[14] Morgan, PH, Mercer, LP and Flodin, NW. General model for nutritional responses of higher organisms. Proceedings of the National Academy of Sciences, USA, v.72, n.1, 1975, p. 4327-4331. 